\title{
CISTO PERIAPICAL INFLAMATÓRIO
}

Pedro Henrique NEIRO, Newton Cesar KAMEI

A paciente E. C., 45 anos, sexo feminino, profissão do lar, leucoderma, casada, procurou o serviço de odontologia do Centro Universitário de Maringá, projeto de lesões bucais (Proleb) queixando-se de "amolecimento dos dentes de baixo". Foi realizada anamnese e exame clínico da paciente. Além da queixa de mobilidade dental, observou-se também necrose pulpar dos elementos 31,32 e 33, através de teste de vitalidade pulpar. Na radiografia panorâmica observou-se presença de lesão radiolúcida, unilocular, localizada em região anterior de mandíbula entre os elementos 33 a 44. Optou-se por enucleação da lesão, sendo realizado previamente biópsia aspirativa, onde foi possível encontrar líquido amarelo citrino. Pela característica clínico-radiográfica, a hipótese diagnóstica foi de cisto periapical inflamatório e tumor odontogênico cístico queratinizante. $O$ resultado anatomopatológico confirma o diagnóstico de um cisto periapical inflamatório. A paciente encontra-se em proservação há um ano, sem sinais de recidiva da lesão.

Palavras-chaves:Cisto; periapical; inflamatório 